\title{
Post-traumatic cerebral sinus thrombosis
}

\author{
Kenta Ochiai, Kazutaka Nishiyama
}

Department of Pediatrics, Kitakyushu Municipal Yahata Hospital, Kitakyushu, Fukuoka, Japan

Correspondence to Dr Kenta Ochiai; ochiai01144110@gmail.com

Accepted 16 December 2020

\section{DESCRIPTION}

A 4-year-old girl with no medical history ran into the road and collided with a car. She was knocked over and injured the back of her head. Her consciousness was clear but she vomited twice. CT scan of the head revealed a linear fracture of the occipital bone across the sinus with no intracranial haemorrhage (ICH) (figure 1). Diagnosis was a concussion and skull fracture, and she was admitted for the follow-up. Her vomiting episodes continued for two or three times per day and irritability arose after hospitalisation. Therefore, on hospital day 3, head MRI performed under sedation revealed a high signal intensity on fluid-attenuated inversion recovery (FLAIR) images in the left sigmoid sinus. No flow void was seen. Although we attempted to perform MR venography (MRV), she woke up from anaesthesia. Further anaesthetic additions were deemed risky and the examination was terminated. At this point, we could not be sure of the thrombosis based on the MRI images alone. However, her irritability persisted for 5 days after the onset, so we performed CT venography (CTV) to confirm the thrombosis. CTV revealed an area of decreased blood flow between the left lateral and sigmoid sinuses. No vascular malformation and ICH were observed. A blood test showed no signs of congenital coagulation disorders. Based on these examinations, the patient was diagnosed with cerebral venous sinus thrombosis (CVST) due to intrinsic vascular damage caused by blunt trauma. ${ }^{1}$ Because of the persistence of irritability over time after the onset, we administered anticoagulation therapy. Her irritability began improving on hospital day 8 . On hospital day 32, MRV showed post-treatment

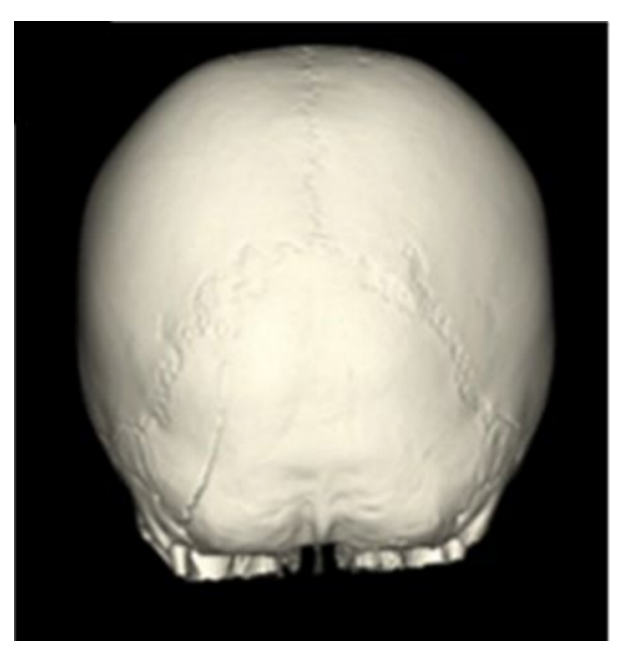

Figure 1 Head CT on admission. The three-dimensional head CT shows occipital fracture.
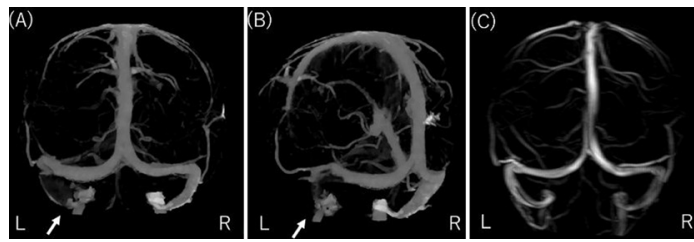

Figure 2 CT venography on 3 days and MR venography on 32 days after trauma. (A, B) CT venography with hypovolaemia from the left sigmoid to the lateral sinuses 3 days after trauma (arrow). (C) MR venography images after completion of anticoagulation therapy showed no hypovolaemia in the cerebral venous sinus 32 days after trauma.

symmetrical blood flow of the cerebral veins (figure 2).

CVST is very rare in children, with 0.67 cases per 100000 population. ${ }^{2}$ Approximately $3 \%-4 \%$ of all cases of paediatric CVST are caused by head injury. ${ }^{3}$ Clinical symptoms may vary widely, including seizures, disability, headache, vomiting and paralysis. Head CT is likely to be selected as an initial diagnostic tool for head trauma because it is rapid and widely available. The sensitivity of the simple CT scan for CVST is only $20 \%-43 \%{ }^{4}$ However, the presence of skull fractures across the sinus and epidural haematoma on CT scan indicates a high risk for CVST. If these findings are recognised and time permits, additional imagining examination, such as CTV and MRV, should be considered. These

\section{Patient's perspective}

Father: We were informed and agreed that my daughter had occipital injury, occipital fractures, and cerebral sinus thrombosis, and underwent anticoagulant therapy. We were relieved to confirm disappearance of the thrombosis and improvement in symptoms. After leaving the hospital, she was fine, but her fear of the car remains.

\section{Learning points}

- We experienced a case of cerebral venous sinus thrombosis caused by head trauma, which disappeared after anticoagulant therapy.

- The differential diagnosis should include the presence of cerebral sinus thrombosis if vomiting persists after head injury.

- A search for cerebral sinus thrombosis (CT venography or MR venography) is necessary if fracture or haematoma around the sinus is observed after head injury. 
imaging tools are useful when making a definitive diagnosis. ${ }^{4}$ Because there are neither specific clinical features nor clear guidelines for diagnosis and of CVST, we believe it important and necessary to consider CVST when a fracture or haematoma around the sinus is observed. Extracaution must be paid to clinical symptoms after a traumatic head injury. However, the effect of anticoagulation treatment for paediatric patients remains unclear. ${ }^{1}$ In this case, we selected anticoagulation therapy because of the persistence of irritability and absence of ICH. The patient's mental status subsequently improved and the thrombus disappeared with no complications.

Acknowledgements The authors would like to thanks Enago (www.enago.jp) for the English language review.

Contributors $\mathrm{KO}$ wrote the manuscript. KN assisted in the preparation of the manuscript. All authors have critically reviewed the manuscript and approved the final version of the manuscript.
Funding The authors have not declared a specific grant for this research from any funding agency in the public, commercial or not-for-profit sectors.

Competing interests None declared.

Patient consent for publication Parental/guardian consent obtained.

Provenance and peer review Not commissioned; externally peer reviewed.

\section{REFERENCES}

1 Hersh DS, Shimony N, Groves ML, et al. Pediatric cerebral venous sinus thrombosis or compression in the setting of skull fractures from blunt head trauma. J Neurosurg Pediatr 2018;21:258-69.

2 deVeber $\mathrm{G}$, Andrew M, Adams C, et al. Cerebral sinovenous thrombosis in children. N Engl J Med 2001;345:417-23

3 Awad A-W, Bhardwaj R. Acute posttraumatic pediatric cerebral venous thrombosis: case report and review of literature. Surg Neurol Int 2014;5:53.

4 Li J, Wei L, Xu B, et al. Risk factors and early diagnosis of cerebral venous sinus occlusion secondary to traumatic brain injury. Neurol India 2015;63:881-8.

Copyright 2021 BMJ Publishing Group. All rights reserved. For permission to reuse any of this content visit https://www.bmj.com/company/products-services/rights-and-licensing/permissions/

BMJ Case Report Fellows may re-use this article for personal use and teaching without any further permission.

Become a Fellow of BMJ Case Reports today and you can:

- Submit as many cases as you like

- Enjoy fast sympathetic peer review and rapid publication of accepted articles

- Access all the published articles

- Re-use any of the published material for personal use and teaching without further permission

Customer Service

If you have any further queries about your subscription, please contact our customer services team on +44 (0) 2071111105 or via email at support@bmj.com.

Visit casereports.bmj.com for more articles like this and to become a Fellow 